\title{
A burguesia enquadrada: Mafalda e sua turma criticam elementos da sociedade burguesa (a naturalização das diferenças, a desumanização e a competição) na aula de História*
}

\author{
The bourgeoisie framed: Mafalda and its group criticize \\ elements of the bourgeois society (the naturalization of the \\ differences, the inhumanuzation and the competition) in the \\ History class
}

\section{Carlos Eduardo Rebuá Oliveira*}

RESUMO

Este trabalho objetiva, a partir de uma perspectiva marxista, refletir sobre a possibilidade de, em se criticando a sociedade burguesa na aula de História, se construir coletivamente, no limite, leituras contrahegemônicas da realidade. Alicerçados no conceito gramsciano de hegemonia e na noção de contrahegemonia, analisamos as histórias em quadrinhos não no intuito de instrumentalizar esta linguagem cada vez mais presente na sala de aula, mas no esforço de compreendê-la como um elemento que pode contribuir bastante para a crítica do real, para a explicitação do momento histórico em que foi produzida, para um ensino de História mais lúdico e crítico ao mesmo tempo. Em termos metodológicos, foram selecionadas três tiras de Mafalda (intituladas "A naturalização das diferenças", "A desumanização" e "A competição"), presentes na obra Toda Mafalda (2002), no intuito de subsidiar as reflexões aqui esboçadas. Este trabalho representa um recorte da dissertação de mestrado defendida no Programa de Pós-Graduação em Educação da UERJ (ProPEd), em março de 2011, sob o título: Mafalda na aula de História: a crítica aos elementos característicos da sociedade burguesa e a construção coletiva de sentidos contra-hegemônicos.

Palavras Chave: Mafalda. Crítica. Ensino de História. Burguesia. Contra-hegemonia.

* Com financiamento do Conselho Nacional de Desenvolvimento Científico e Tecnológico (CNPq).

* Bacharel e licenciado em História pela Universidade Federal Fluminense. Mestre em Educação pelo Programa de PósGraduação em Educação da UERJ (ProPEd). 
The purpose of this work, from a marxist point of view, is to think about the possibility in criticizing the bourgeosie society in History classes, to set up colectively, at last, anti-hegemonic reality readings. Based upon Gramsci concept of hegemony and on anti-hegemony notion, we have analyzed the comics not with the intention of making this language more and more present in the classes but with the attempt of understanding them as a tool that may contribute a lot for a real criticism and for the explicitness of the historic moment in which they were created, for a teaching, at the same time, more playful and critic. In methodological terms, we have selected three Mafalda's strips (named "The naturalization of the differences", "The inhumanization" and "The competition"), shown on Toda Mafalda (2002) aiming to replace the insights herein sketched. This work is a part of the master's degree lecture, read at the Postgraduation Program in Education of UERJ (ProPed) in March 2011, under the title of Mafalda in The History class: a criticism of the bourgeoise society charactheristic elements and the collective making-up of hegemonic meanings.

Keywords: Mafalda. Criticism. History teaching. Bourgeoise. Anti-hegemony

\section{Histórias em quadrinhos na sala de aula}

Até pouco tempo, as histórias em quadrinhos "entravam" na escola pela "porta dos fundos" e na universidade, após um pedido de desculpas. Eram considerados uma subarte, uma subliteratura (LUYTEN, 1984, p. 8), representando uma linguagem "menor" e assumindo um caráter apenas de brincadeira, diversão, passatempo. Felizmente, muita coisa mudou nestes últimos trinta anos no que diz respeito ao olhar acadêmico sobre as hq's ${ }^{1}$. No entanto, apesar da recente profusão de trabalhos acerca desta linguagem e sua relação com a educação, estudar quadrinhos ainda representa tarefa difícil não apenas pela bibliografia acadêmica ainda incipiente, mas sobretudo pela dificuldade em se discutir tal linguagem sem incorrer no mecanicismo ou no utilitarismo, ou em outras palavras, estudar as hq's sem enjaulá-las na categoria de "ferramenta", de "carta na manga" do professor.

Corroborando a dificuldade acima apresentada existe também o fato de muitas abordagens pedagógicas acerca das hq's estarem descoladas do "mundo real", circunscritas apenas ao nível teórico, sem sintonizar-se com o ambiente da sala de aula, com o trabalho docente e sem analisar as condições de produção de tais materiais. As hq's não existem dissociadas do mundo real, descontextualizadas; não atuam como "receita de bolo", "vara de condão" ou ferramenta lúdica (para tornar a aula mais atraente, descontraída, para "pescar" alunos), descoladas da realidade objetiva e dos agentes sociais que a engendram (artistas) e a interpretam (professores, alunos).

\footnotetext{
${ }^{1}$ Abreviação comum para histórias em quadrinhos.
} 
Da ousadia em analisar hq's sob referencial marxista, esperamos contribuir para ambos os campos, politizando o estudo da arte sequencial e ampliando os horizontes do marxismo em suas abordagens educacionais, empreendendo, assim, uma "aventura" poucas vezes explorada.

\section{Mafalda e sua turma}

Figura 1- Mafalda e sua turma

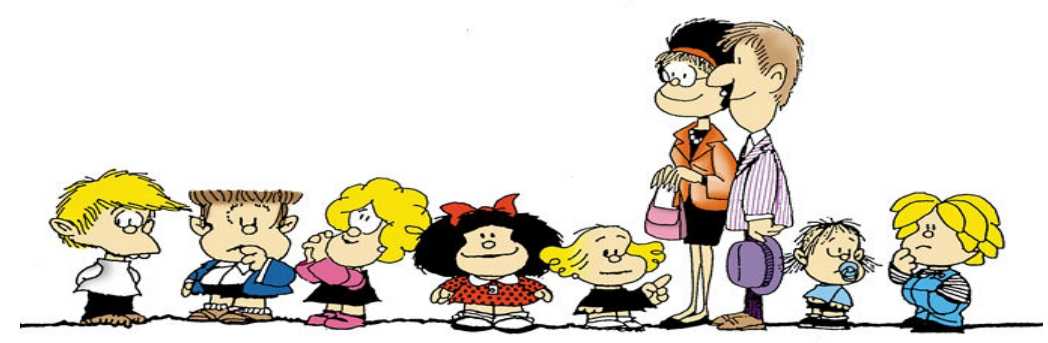

Fonte: Mafalda online (2011)

Mafalda (QUINO, 2002, p.8) é a personagem de hq's mais popular da Argentina e uma das mais conhecidas do mundo, a despeito de sua curta trajetória (1964 a 1973). Seja como souvenir, estampando camisas, cartazes do movimento estudantil, ou através dos já clássicos livroscoletânea, a quase "cinquentona" Mafalda insiste em se fazer presente, talvez porque suas indagações, críticas, provocações, ainda suscitem muitas reflexões em espaços e tempos diferentes.

Os interlocutores de Mafalda também representam personagens extremamente ricas e complexas, sendo fundamentais para a caracterização da menina argentina, pois é em sua relação com Miguelito, Susanita, seus pais, etc. (que Quino chama de contra-personajes), que Mafalda se constitui como sujeito e que o leitor consegue caracterizar cada personagem. (TRILLO; SACCOMANNO, 1980, p. 161).

Susanita, é a "burguesinha" fofoqueira, egoísta, racista e briguenta cujo principal projeto de vida é casar com um "bom partido" e ter muitos filhos. Não se preocupa com os problemas do mundo, pois o que importa mesmo é a "aparência" e a segurança de sua vida calculada e fútil. Está sempre em conflito com a questionadora Mafalda (por naturalizar a desigualdade entre homens e mulheres, pobres e ricos na sociedade) e com Manolito, por quem tem um grande desprezo. Tem uma paixão recolhida por Felipe. 
O dentuço Felipe, mais velho do que todos (tem sete anos enquanto Mafalda, Manolito e Susanita têm seis ${ }^{2}$ ), é o sonhador de imaginação fértil, vidrado em hq's de aventuras (sobretudo o "Cavaleiro Solitário"). Extremamente preguiçoso, não gosta de ir à escola e está sempre adiando o momento de fazer as tarefas pedidas pela professora. Tímido, é apaixonado pela Brigitte Bardot e é a personagem que tem mais identidade com Quino (segundo o próprio autor).

O empresário-mirim da turma, Manolito (o segundo a partir da direita, na Figura 1), tem sua visão de mundo norteada fundamentalmente pelo capital, principalmente quando tenta "vender" a qualquer custo os "singulares" produtos do Armazém de seu pai (que é um imigrante espanhol), o Don Manolo ("que vende mais barato", slogan divulgado por ele frequentemente), onde trabalha (ele é o único da turma que trabalha e estuda). Ambicioso, bruto, materialista, fã dos homens de Wall Street, porém de grande coração, apesar de evitar qualquer demonstração de carinho, emotividade. Como Susanita, Manolito tem seu projeto de vida definido: ser dono de uma rede de supermercados! Além disso, odeia as opiniões politizadas de Mafalda, os "cabeludos" dos Beatles, os hippies, e seu boletim na escola é uma coleção de notas baixas.

O simpático e egocêntrico Miguelito (o último da direita) é um dos pontos altos da turma. Vaidoso ao extremo, tem cinco anos e está sempre sonhando com o estrelato (ama o jazz e sonha ser um famoso trompetista "negro") e filosofando sobre quase tudo que o cerca, inclusive conferindo vida a coisas inanimadas, como sapatos e tomadas. Neto de um fascista admirador de Mussolini, Miguelito está sempre a interrogar, de forma ingênua, as contradições da realidade.

A pequena Libertad, uma "miniatura à esquerda" de Mafalda (que na Figura 1 também está à sua esquerda), foi a última a aparecer na turma (sua idade não é conhecida), em 1970. Extremamente crítica, sincera e direta, a baixinha é filha de hippies (o pai, socialista, trabalha num emprego insignificante e a mãe em casa, como tradutora de francês) e uma entusiasta das revoluções, das lutas sociais, dos trabalhadores, das greves. Com certeza a escolha do nome e seu tamanho diminuto revelam o olhar crítico de Quino a respeito da liberdade, quase não "vista" pela grande maioria dos indivíduos. Defende constantemente a simplicidade, apesar de inúmeras vezes ir de encontro ao que é simples.

Guile (Guillermo) é o irmão caçula de Mafalda e o único que aparece na turma ainda na barriga da mãe (surge em 1968). Através de Guile, Quino mostra de maneira divertida as diversas fases do desenvolvimento da criança (mamar, engatinhar, andar, falar, etc.) bem como suas reações diante do "mundo novo", descoberto a cada "engatinhada" (dividir quarto com a irmã, como mostra a tira acima, por exemplo). Guile, como é comum em crianças de sua idade, incorpora em seu discurso falas "adultizadas", e tem muito do olhar crítico de Mafalda (afinal, quem sai ileso da convivência com ela?). Assim como a irmã, Guile é um transgressor, potencializado pela tenra idade, que não impõe censuras tampouco busca se adequar a

\footnotetext{
${ }^{2}$ Tendo como referência o ano de 1964, quando surge a turma.
} 
convenções e regras. Nas diversas tiras em que aparece, alterna precocidade e ingenuidade. Gosta de chupeta on the rocks e assim como Felipe, é apaixonado pela Brigitte Bardot.

Os pais de Mafalda representam a classe média latino-americana e aparecem em um grande número de tiras. Alienados, limitados intelectualmente, endividados e sempre à espera das próximas férias, têm como rotina os questionamentos da filha (o que os leva com freqüência à farmácia, para comprar o calmante Nervocalm) e posteriormente, as travessuras de Guile. O pai (Quino nunca disse seu nome! ${ }^{3}$ ) é funcionário de uma companhia de seguros (trabalho que odeia), adora jardinagem e está constantemente preocupado com os "sinais" da idade. A mãe (Raquel) é dona-de-casa e por isso não cursou a faculdade, opção abominada por Mafalda, que repetidamente a adjetiva de medíocre. Suas sopas representam uma tortura para Mafalda.

A "filósofa" de seis anos, invocada, utópica e questionadora das injustiças do mundo, libertária, politizada, fã de Beatles e avessa a qualquer tipo de sopa, dialoga com diversas faixas etárias e classes sociais ${ }^{4}$, sendo bastante utilizada em livros didáticos, sejam eles de Gramática, História, Geografia ou Filosofia.

A personagem de Quino constrói sua fala, em grande parte das tiras, de duas formas: ou a partir do questionamento dos adultos (geralmente seus pais), no intuito de dirimir as dúvidas que tiram seu sono, ou na interação com as outras personagens, de mesma idade, buscando entender o mundo que os cerca (por que existem guerras? por que a mãe trabalha em casa e o pai não?), a partir dos referenciais de que dispõem.

Obviamente Mafalda não é um quadrinho infantil, dialogando diretamente com um público majoritariamente de adolescentes e adultos. Desta forma, a personagem de Quino oscila muitas vezes entre a caracterização de uma criança típica, com tudo que lhe possa ser atribuído (medo, ingenuidade, dependência dos pais), em que o concreto norteia sua concepção de mundo, e uma criança excepcionalmente ${ }^{5}$ lúcida, crítica e profunda conhecedora da realidade na qual está inserida (quando a "voz" de Quino se faz mais presente), que constrói metáforas ("saindo" da dimensão do concreto, que caracteriza a criança em seus anos iniciais) e faz associações elaboradas, discutindo de igual pra igual com as pessoas mais velhas e, na maioria das vezes, colocando-as em posição de "xeque-mate".

Mafalda e sua turma abordam temas característicos (mas não exclusivos) do cotidiano latino-americano (machismo, regimes militares, desigualdade social, dependência externa, etc.) contexto temporal e espacial de sua produção. Todavia, é justamente sua crítica contundente à humanidade - que segundo Quino (ARAUJO, 2010) "sempre esteve mal" - que confere a esta obra

\footnotetext{
${ }^{3} \mathrm{Na}$ internet, foram encontrados dois supostos nomes para o pai de Mafalda: Pelicarpo e Tomas, ambos sem nenhuma confirmação na obra de Quino.

${ }^{4}$ Apesar de ser muito mais direcionada para o público jovem/adulto.

${ }^{5}$ Excepcional não no sentido de uma criança superdotada, mas de uma criança que compreende o mundo e o interpela de uma maneira que não é comum.
} 
um caráter "universal" (assim como os Peanuts), sendo reproduzida em todo o mundo, com grande aprovação dos leitores (ainda que, obviamente, muitas tiras só sejam compreendidas por nós, latino-americanos e sobretudo, pelos argentinos). Uma destas "críticas universais" de Mafalda é a crítica à burguesia (classe hegemônica mundialmente), que analisaremos mais à frente.

Antes é necessário explicitar o conceito de contra-hegemonia, oriundo da concepção de hegemonia de Gramsci e que alicerça nossas análises tanto na dissertação que deu origem a este artigo, quanto no próprio artigo. Em breves palavras, defendemos que é possível na aula de História, coletivamente, a partir da crítica de Mafalda e sua turma aos elementos que caracterizam a sociedade burguesa ${ }^{6}$, forjar sentidos contra-hegemônicos, opostos ao mundo material e simbólico construído pela burguesia ao longo dos últimos três séculos.

\section{A contra-hegemonia}

É importante pontuar que o conceito de contra-hegemonia não foi criado por Gramsci. Corresponde a uma interpretação do conceito de hegemonia do filósofo italiano a partir de uma perspectiva crítica, atualizada e, sobretudo estratégica, por parte de inúmeros marxistas (por exemplo, os brasileiros Leandro Konder e Carlos Nelson Coutinho e os britânicos Raymond Williams e Terry Eagleton), objetivando traduzir/demarcar, em termos de luta ideológica e material, um projeto antagônico de classe, em relação à hegemonia burguesa. $\mathrm{O}$ termo, que se consolidou pelo uso, significa que a luta é contra uma hegemonia estabelecida, uma luta que objetiva a construção de uma nova hegemonia, e que por isso, corresponde a um projeto de classe distinto. Como corresponde a uma interpretação, tal conceito oferece muitas dificuldades para quem se "aventura" a explorar seu (s) significado (s). Além de escassa na literatura marxista, a definição do conceito pode ser encontrada sob os mais distintos espectros político-ideológicos.

Longe de incorporar um neologismo, utiliza-se um conceito legitimado por diversos intelectuais importantes dentro do campo marxista (ainda que poucos o definam), que fazem uso da "contra-hegemonia" querendo apontar para outro projeto de classe, outro mundo possível.

De acordo com Eduardo Granja Coutinho (2008, p.77),

Parafraseando Marx, pode-se dizer que toda hegemonia traz em si o germe da contra-hegemonia. Há, na verdade, uma unidade dialética

\footnotetext{
${ }^{6}$ Na dissertação, outros onze temas são analisados, a partir de quinze tiras presentes em Toda Mafalda (QUINO, 2002). São eles: a "democracia", o individualismo, o estímulo ao consumo, a "igualdade", a valorização do lucro, a propriedade privada, o progresso e o livre-comércio.
} 
entre ambas, uma se definindo pela outra. Isto porque a hegemonia não é algo estático, uma ideologia pronta e acabada. Uma hegemonia viva é um processo. Um processo de luta pela cultura.

E recuperando Raymond Williams, a partir de Chauí (1986, p. 22), frisa que a hegemonia "Deve ser continuamente renovada, recriada, defendida e modificada e é, continuamente, resistida, limitada, alterada, desafiada por pressões que não são suas" (CHAUÍ, 1986, p. 22). Para Williams (1979, p. 115-116), a hegemonia

[...] também sofre uma resistência continuada, limitada, alterada, desafiada por pressões que não são as suas próprias pressões. Temos então de acrescentar ao conceito de hegemonia o conceito de contrahegemonia e hegemonia alternativa, que são elementos reais e persistentes na prática.

Por sua vez, Terry Eagleton, discípulo de Williams, afirma que "qualquer poder governante é forçado a travar combate com forças contra-hegemônicas de maneiras que provam ser parcialmente constitutivas de seu próprio domínio" (EAGLETON, 1997, p. 107).

A hegemonia corresponde à liderança de uma classe e suas frações sobre as demais; corresponde a uma direção política, cultural que é exercida por uma classe em aliança ou não com outras. Logo, um movimento contra-hegemônico sempre compreenderá a luta de classes, significando um projeto distinto de sociedade, como por exemplo, o comunismo em relação ao capitalismo.

Fundamental para nossas pretensões neste trabalho é a compreensão de que toda contrahegemonia é uma luta em duas frentes: a material (que Gramsci chama de "conteúdo" (EAGLETON, 1997, p. 109) e a ideológico-cultural (que Gramsci chama de "forma"). Sobre esta última, que na concepção gramsciana equivale ao campo do consenso7, o presente trabalho dedica atenção especial, pensando possibilidades de, na aula de História, em questionando/criticando os fundamentos da sociedade burguesa, o senso comum, os discursos hegemônicos legitimadores da divisão da sociedade em classes, contribuir para a construção de uma reforma intelectual e moral, como defendia Gramsci, apontando para a construção de um outro mundo, possível e necessário.

Conquistar a hegemonia significa, para Gramsci, estabelecer uma liderança moral, intelectual, política, difundindo sua própria "concepção de mundo"8 por toda a sociedade,

\footnotetext{
${ }^{7}$ Para Gramsci, o exercício da hegemonia compreende dialeticamente a força (domínio) e o consenso (direção).

${ }^{8}$ Como Gramsci definia a ideologia.
} 
igualando o próprio interesse (da classe hegemônica) com o da sociedade em geral. Acanda (2006, p. 207) nos ajuda a compreender a importância da cultura e da ideologia na construção de qualquer movimento contra-hegemônico, quando afirma que "A construção de uma nova hegemonia emancipadora implica, em Gramsci, a realização de uma reforma intelectual e moral que seria capaz de criar uma nova visão de mundo e uma nova ideologia do povo". Corroborando sua visão, Eagleton (1997, p. 106) pontua que:

Na sociedade moderna, então, não é suficiente ocupar fábricas ou entrar em confronto com o Estado. $O$ que também deve ser contestado é toda a área da "cultura", definida em seu sentido mais amplo, mais corriqueiro. [...] qualquer "contra hegemonia" deve levar sua campanha política até esse domínio, até agora negligenciado, de valores e costumes, hábitos discursivos e práticas rituais.

Entendemos o espaço contraditório e dinâmico da sala de aula, marcado fortemente pelo conflito, como um espaço de disputas fundamental, onde concepções críticas de mundo podem ser construídas, num movimento que não se esgota apenas na negação da hegemonia burguesa dominante, mas que "ousa" outros sentidos possíveis, outros caminhos, contra-hegemônicos no limite.

\section{A crítica à burguesia através de Mafalda e sua turma}

Chamamos de elementos característicos da sociedade burguesa aqueles traços distintivos que permitem caracterizar o modo de vida burguês (muitos deles presentes nos livros didáticos, nos conteúdos programáticos da disciplina de História) na contemporaneidade. $\mathrm{O}$ fato, por exemplo, da propriedade privada e sua inviolabilidade serem anteriores ao surgimento da burguesia, não invalida a compreensão de que a conquista do Estado por esta classe, a partir do século XVII e sobretudo no XVIII, consolida a propriedade privada como um alicerce fundamental da sociedade contemporânea. Se alguns destes elementos característicos da sociedade burguesa podem ser entendidos como "fundamentos" deste tipo de sociedade (a democracia burguesa, o individualismo, a igualdade jurídica9, exaltados como virtudes do modus vivendi burguês), outros explicitam, a partir de uma perspectiva crítica, os efeitos sociais produzidos pela sociedade burguesa, como a desumanização e a naturalização das diferenças. A definição de burguesia de Engels, presente numa nota à edição inglesa de 1888 do Manifesto Comunista, nos parece bastante significativa: "a classe dos capitalistas modernos, proprietários

${ }^{9}$ Outros elementos característicos da sociedade burguesa analisados na dissertação. 
dos meios da produção social e empregadores do trabalho assalariado" (ENGELS apud BOTTOMORE, 2001, p. 38).

As três tiras a seguir, com Mafalda, sua família e amigos, abordam elementos presentes na sociedade burguesa e que representam condições imprescindíveis para que a hegemonia desta classe seja garantida. As análises de cada tira correspondem a uma abordagem crítica, alicerçada sobretudo no materialismo histórico e sintonizada com a necessidade de superação da sociedade burguesa, materialmente e ideologicamente. Não se trata de um "manual" de como analisar Mafalda, mas uma possibilidade em meio a tantas outras, de se analisar política e criticamente as histórias em quadrinhos, fruto de inúmeras análises descontextualizadas, acríticas, despolitizadas.

Tira 1 - A naturalização das diferenças
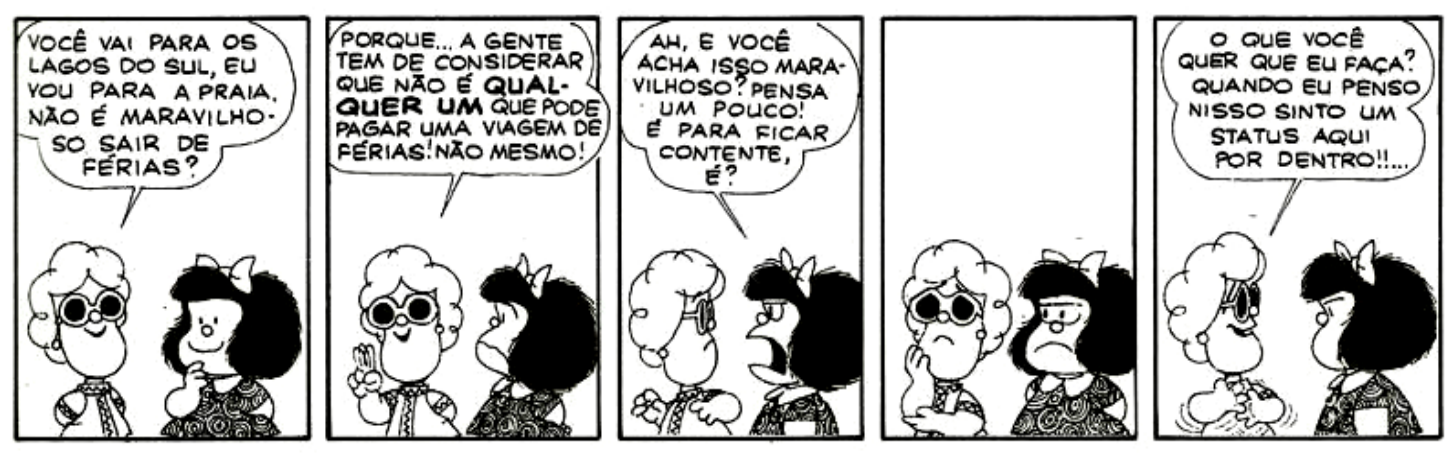

Fonte: Quino (2002, p. 139).

A primeira tira mostra Susanita e Mafalda em cinco quadros. As duas amigas conversam sobre seus destinos de férias, vestidas com roupas que não costumam usar no dia-a-dia. Susanita, de óculos escuros e com a soberba que lhe é característica, comenta com Mafalda sobre os lugares para onde viajarão: esta para os lagos do sul e aquela para a praia. Mafalda se mostra feliz, só de imaginar quão divertida será a viagem. Então, a burguesinha Susanita tece mais um de seus comentários elitistas: "Porque... a gente tem de considerar que não é qualquer um que pode pagar uma viagem de férias!" (grifo do autor), gesticulando com o dedo indicador em sinal de "não". E enfatiza: "Não mesmo!". Mafalda, que não tolera o tom aristocrata da amiga, pergunta exaltada: “Ah, e você acha isso maravilhoso? Pensa um pouco! É para ficar contente, é?". Susanita parece se assustar com a fala da amiga. O penúltimo quadro mostra Susanita pensativa, demonstrando certa culpa pelo que disse, enquanto Mafalda a observa, desapontada. Desculpas? Culpa? Não! Susanita não se importa, como de praxe, com as "questões da consciência", expondo de maneira natural que não tem o que fazer em relação a isso, já que sente "por dentro" um enorme status quando fala este tipo de coisa, ou seja, quando naturaliza as diferenças. 
A concepção de mundo (ideologia) de Susanita é a concepção burguesa, que entende o mundo a partir do individualismo e da meritocracia. Após enfrentar e sepultar a sociedade feudal, com seus privilégios de nascimento (que de partida, já separava os "capazes" dos "nãocapazes"), a burguesia soube, como nenhuma outra classe, colocar ao alcance de todos, ao menos na teoria, a possibilidade de se tornar "alguém", de ter direitos, privilégios, de ter "status". Todavia, na visão burguesa de sociedade não há espaço para todos, ainda que no nível do discurso, este espaço esteja "livre" para ser ocupado por quem quer que seja.

Naturalizar as diferenças corresponde a uma característica marcante da sociedade burguesa e Quino soube abordar a questão de maneira crítica e contundente. É bastante comum nos programas políticos de partidos burgueses (no caso brasileiro, o PSDB representa um ótimo exemplo), o "discurso da competência", ou seja, a idéia de que existem pessoas/grupos mais "capazes" e/ou "competentes" na realização de ações específicas: legislar, gerenciar/gerir" governar, "fazer política", etc. Chauí afirma a existência de uma "ideologia da competência", que defende que "não é qualquer um que pode em qualquer lugar e em qualquer ocasião dizer qualquer coisa a qualquer outro" (CHAUÍ, 2006, p. 77). Para a filósofa brasileira, tal ideologia, que atua com a figura do "especialista", cria a clivagem social entre os competentes (que sabem) e os incompetentes (que obedecem).

Ao nível do senso comum na sociedade burguesa, são típicas frases como "ter um carro desses não é para qualquer um mesmo!", ou então, "uma mansão dessas é pra quem pode", que difundem e legitimam a ideologia burguesa no imaginário das demais classes sociais. Para que alguns acumulem capital, usufruam de bons planos de saúde e de previdência, desfrutem de viagens inesquecíveis para a praia ou para os lagos do sul, é preciso que muitos não tenham condições alguma. É a boa e velha escassez regulando o preço das mercadorias e a taxa de maisvalia.

Tira 2 - A desumanização
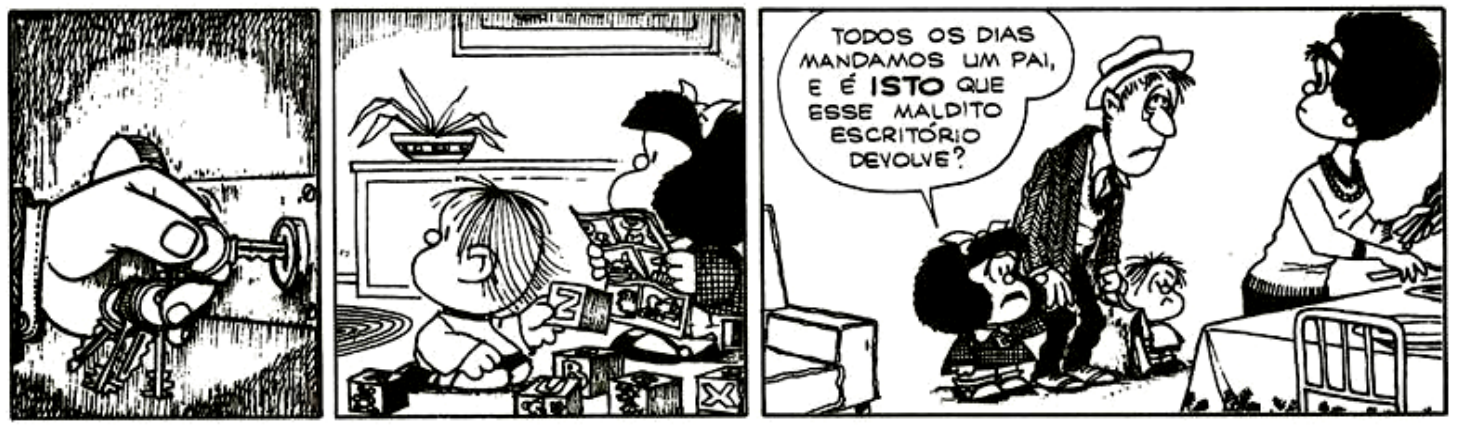

Fonte: Quino (2002, p. 300).

${ }^{10}$ Termos típicos do discurso empresarial contemporâneo. 
A Tira 2 tem como protagonista o pai de Mafalda e compreende três quadros apenas, que mostram o patriarca da família chegando do trabalho, extremamente cansado. Os dois primeiros quadros não têm fala: no primeiro, aparece uma mão com um molho de chaves abrindo uma porta (não sendo possível saber quem é); no segundo, surgem Guile e Mafalda, que brincam e lêem, respectivamente, na sala de casa (ainda assim, não é possível saber, no segundo quadro, quem está chegando). O último quadro da tira mostra o pai das crianças exausto, moribundo, apático, devido à rotina estressante do escritório de seguros onde trabalha. Mafalda e Guile seguram suas mãos quase que o apoiando e o levam até Raquel, sua mãe. A única fala da tira é de Mafalda, que pergunta à mãe: "todos os dias mandamos um pai, e é isto (grifo do autor) que esse maldito escritório devolve?"

Mais uma vez a crítica de Quino mostra-se bastante atual, retratando a extrema exploração física e mental dos trabalhadores no capitalismo, alienados da produção e, logo, segundo Marx, desumanizados. Para o comunista alemão, o processo de trabalho, que é social, coletivo e nunca individual, é uma condição da existência humana, comum a todas as formas de sociedade. Esta atividade social do homem transforma a natureza e o próprio homem, humanizando-o.

\begin{abstract}
Pode-se distinguir os homens dos animais pela consciência, pela religião ou pelo que se queira. Mas eles mesmos começam a se distinguir dos animais tão logo começam a produzir seus meios de vida, passo que é condicionado por sua organização corporal. Ao produzir seus meios de vida, os homens produzem, indiretamente, sua própria vida material. [...] Tal como os indivíduos exteriorizam sua vida, assim são eles. O que eles são coincide, pois, com sua produção, tanto com o que produzem como também com o modo como produzem. O que os indivíduos são, portanto, depende das condições materiais de sua produção. (MARX; ENGELS, 2009, p. 87).
\end{abstract}

Leandro Konder, alicerçado em Marx, afirma que "O trabalho é a primeira atividade do ser humano como ser humano. É pelo trabalho que passa a existir a contraposição sujeito/objeto. [...] O trabalho é a atividade pela qual o ser humano se criou a si mesmo; pelo trabalho ele transforma o mundo e se transforma" (KONDER, 2002, p. 35).

No entanto, no modo de produção capitalista o trabalho humano assume feições desumanas, pois os homens, que produzem os bens materiais indispensáveis à vida, não se realizam como seres humanos em suas atividades: o produto de seu trabalho não é seu, assim como não são seus os meios de produção. A criação (produto) do trabalhador se apresenta a ele 
como algo estranho ${ }^{11}$ e o trabalho, na indústria capitalista, é encarado pelos trabalhadores como algo odiável, que lhes é imposto, que os oprime e exaure física e mentalmente.

O capitalismo caminha na contramão da humanização - esta é sua natureza. A organização do trabalho e da produção no capitalismo busca de maneira incessante a acumulação de capital, em detrimento da satisfação das necessidades humanas.

Quanto menos comeres, beberes, comprares livros, fores ao teatro, ao baile, ao restaurante, pensares, amares, teorizares, cantares, pintares, esgrimires etc., tanto mais tu poupas, tanto maior se tornará o teu tesouro, que nem as traças nem o rouco corroem, teu capital. Quanto menos tu fores, quanto menos externares a tua vida, tanto mais tens, tanto maior é a tua vida exteriorizada, tanto mais acumulas da tua essência estranhada (MARX, 2008, p. 141-142).

Transformado em mercadoria, "coisificado", o trabalhador "se torna tanto mais pobre quanto mais riqueza produz [...] se torna uma mercadoria tão mais barata quanto mais mercadorias cria" (MARX, 2008, p. 80). Para Marx, o trabalho não produz apenas mercadorias, mas produz também a si mesmo e ao trabalhador como uma mercadoria, enquanto produz, efetivamente, mercadorias em geral.

Nos mesmos Manuscritos econômico-filosóficos, no Caderno 1, quando analisa os salários, Marx compara o homem, na sociedade regulada pelo capital, a qualquer mercadoria: "a procura por homens regula necessariamente a produção de homens assim como de qualquer outra mercadoria" (MARX, 2008, p. 24). Sujeito da mesma forma à lei da oferta e procura (que torna miserável ou mesmo mata o trabalhador, em períodos de grande oferta), o homem não se diferencia de uma lata de leite ou de um sapato:

A existência do trabalhador é, portanto, reduzida à condição de existência de qualquer outra mercadoria. O trabalhador tornou-se uma mercadoria e é uma sorte para ele conseguir chegar ao homem que se interesse por ele. E a procura, da qual a vida do trabalhador depende, depende do capricho do rico e capitalista. (MARX, 2008, p. 24)

Com o salário correspondendo ao mínimo necessário para que o trabalhador consiga desempenhar suas funções, sustentar sua família e se reproduzir (MARX, 2008, p. 24), sendo

\footnotetext{
${ }^{11} \mathrm{O}$ mesmo se dá em relação aos capitalistas, que embora tirem proveito da alienação dos trabalhadores, também sofrem as conseqüências desumanizadoras da divisão social do trabalho. Os capitalistas também se alienam, uma vez que não têm a experiência cotidiana do trabalho produtivo e sua criação também se aliena deles, pois não se reconhecem de maneira clara nela. Em suma, o operário se aliena em sua atividade produtiva e o capitalista em sua atividade improdutiva.
} 
que muitos não conseguem alcançar nem este "mínimo" e outros tantos, na informalidade, nem tem salários; sujeitos a péssimas condições de trabalho, que provocam profundos desgastes físicos (audição, visão, dores generalizadas, cansaço extremo, etc.) e mentais (depressão, pânico, insônia, falta de concentração, etc.); pressionados pela competição, cada vez mais estimulada pelas metas, pelo desemprego, pelos "mais capacitados", pelos mais jovens; substituídos parcialmente ou totalmente em diversos setores por tecnologias que visam ao aumento da produtividade, da taxa de lucro; expostos a cargas horárias exaustivas que extraem sobretrabalho quase sem limites; perdendo ou tendo flexibilizados gradativamente seus direitos, os trabalhadores têm sido "devolvidos" para suas casas cada vez mais desprovidos de sua humanidade, de sua capacidade inventiva, cada vez mais mercadoria, mais "coisa" (a palavra isto, utilizada por Mafalda, corrobora esta característica), cada vez mais fragmentados, divididos enquanto classe.

A tira de Quino, que representa um trabalhador que pode ser da década de 1920 ou da nossa década, mostra, na perspectiva das crianças, os efeitos da exploração desumana do capital, que "devolve" no fim do dia, em frangalhos, um pai que pela manhã estava disposto, saudável, com energia. Para Mafalda e Guile, é revoltante receber seu pai desta forma: com olheiras, com a postura de um idoso, com a roupa amarrotada, com expressão de derrota. Reclamam com a mãe, que não trabalha num escritório (mas que também se desgasta nos afazeres domésticos) e é a única outra pessoa para quem eles podem expor sua indignação. A resposta para a pergunta de Mafalda, como foi dito, é bastante complexa. Ainda bem que Marx tomou sopa quando criança ${ }^{12}$...

Tira 3 - A competição
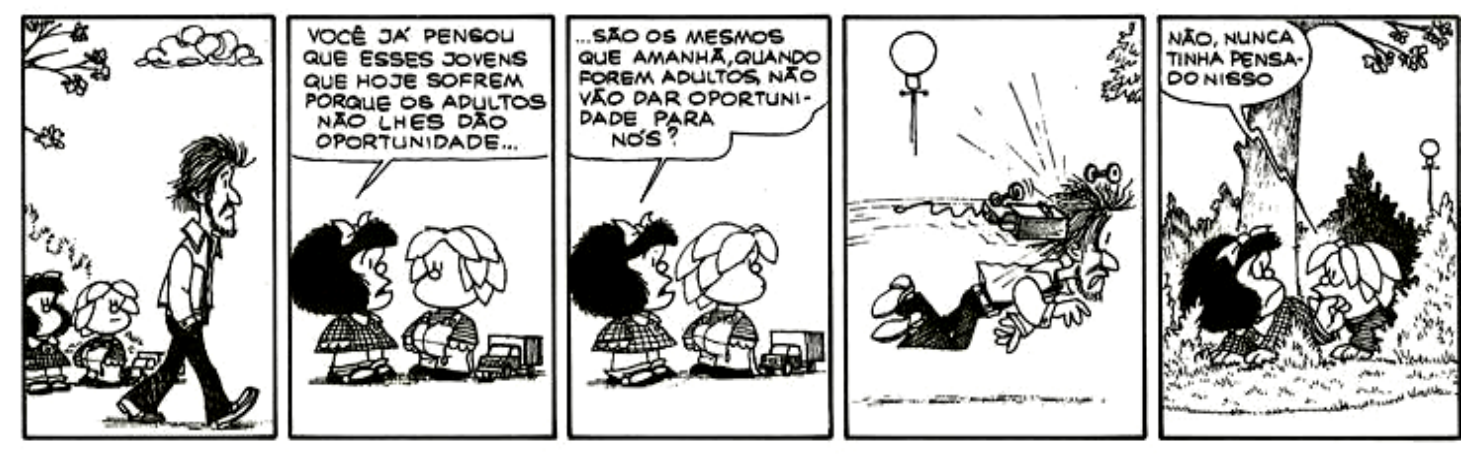

Fonte: Quino (2002, p. 344)

A Tira 3 tem Mafalda e Miguelito como protagonistas. Os dois, brincando numa praça (Miguelito com um carrinho puxado por uma cordinha), observam um jovem caminhando (a

\footnotetext{
${ }^{12}$ Em alusão a uma tira (QUINO, 2002, p. 8) em que Mafalda, triste em frente a um prato de sopa, ouve sua mãe dizer para ela comer tudo porque quem não toma sopa não cresce, fica sempre criança, não se tornando nunca gente grande. A resposta de Mafalda dispensa comentários: "como este mundo seria tranquilo se Marx não tivesse tomado sopa!".
} 
primeira tira é sem falas), com aparência séria. Nos dois próximos quadros, Mafalda pergunta a Miguelito: "você já pensou que esses jovens que hoje sofrem porque os adultos não lhes dão oportunidade... (neste momento Miguelito "se desliga" do que a amiga lhe diz e observa o rapaz, que já se distanciara deles) são os mesmos que amanhã, quando forem adultos, não vão dar oportunidade para nós?" O quarto quadro da tira mostra o rapaz sendo fortemente atingido na nuca pelo carrinho de brinquedo de Miguelito, o que provoca sua queda. No último quadro, o amigo de Mafalda (escondido com ela atrás de arbustos), cuja resposta havia sido adiada em virtude do arremesso certeiro, diz baixinho: "não, nunca tinha pensado nisso".

Talvez a competição, junto do individualismo e do consumo ${ }^{13}$, represente uma das características mais presentes, ao nível do senso comum, quando se pensa/discute o mundo contemporâneo, a sociedade de matriz capitalista.

Dez entre cada dez especialistas em carreiras para o mercado colocam a "competitividade" como um dos atributos fundamentais para qualquer "candidato ao sucesso", seja ele uma empresa ou um jovem formando do ensino superior. Em todos os reality shows, no Brasil e no mundo, os candidatos mais "fortes", mais respaldados pelo "voto do público", são aqueles que conseguem competir com mais arrojo e frieza. As corporações e economias nacionais mais invejadas e exaltadas nas revistas de finanças e no main stream empresarial são aquelas onde o nível de competição é extremamente alto. Times ou seleções de futebol, vôlei, basquete, bem como equipes de automobilismo e atletas de esportes individuais, normalmente têm sua trajetória vitoriosa associada ao alto nível de competitividade que possuem. Alguns acreditam que a competição é algo intrínseco ao ser humano, podendo inclusive ser comprovada biologicamente. Na sociedade burguesa, o lema do Barão de Coubertin ("o importante não é vencer, mas competir") não é muito bem-vindo, sobretudo porque a vitória, como dissemos, está geralmente associada ao nível de competitividade de cada um.

A fala de Mafalda, profundamente fatalista, corresponde a uma concepção de mundo infelizmente bastante difundida nos dias de hoje. Melhor do que concorrer é não medir esforços para eliminar todo e qualquer adversário que obstaculize seus objetivos. O filme "O Corte" (2005), do diretor grego Costa-Gavras, trata este assunto de forma magistral, ao narrar a história de um engenheiro francês bastante capacitado que é demitido de seu emprego. Desesperado após dois anos sem trabalhar, Bruno Davert decide "arremessar seu carrinho" (leia-se: assassinar) não apenas contra o atual ocupante de seu antigo cargo, mas também contra todos os postulantes a ele.

O "trote" nos calouros das universidades, escolas militares, dentre outras, é outro bom exemplo. Na contramão da célebre passagem bíblica "não faça com os outros o que não gostaria que fizessem contigo", os trotes, entendidos como um rito de passagem bastante consagrado,

\footnotetext{
${ }^{13}$ Analisados na dissertação.
} 
defendem que seja feito com os novatos aquilo a que os ex-novatos, hoje veteranos, foram submetidos. No entanto, em diversos casos, a "vingança" dos veteranos é bem mais severa do que a que sofreram no passado, sendo comuns nos noticiários, histórias de violência que às vezes terminaram de maneira trágica.

Arremessar o carrinho contra o rapaz, um dos futuros responsáveis pelas oportunidades para as crianças de hoje, significa, para Miguelito, tentar impedir um novo ciclo de vinganças, trotes, "cortes", semelhantes aos que o jovem agredido devia estar passando naquele momento (segundo dedução de Mafalda), por causa do egoísmo dos adultos. Obviamente Miguelito não só pensou sobre o que Mafalda lhe disse como tentou impedir, a seu modo, que no futuro não faltem oportunidades para ele, Mafalda, e tantas outras crianças.

De maneira divertida, Quino mostra como muitas vezes, na sociedade contemporânea, as ansiedades, os receios e as concepções de mundo dos adultos são transferidas para as crianças, que passam a se preocupar com questões que não dizem respeito a seu cotidiano: desemprego, salário, contas, vestibular, carreira, "diferencial profissional", etc. Idéias como "os melhores são selecionados ainda no berço"; "você começa a passar no vestibular no sexto ano do ensino fundamental"; "sem o inglês, e agora, mais um idioma, você não conseguirá nada no mercado"; "os mais 'aptos' chegaram onde estão porque foram pragmáticos, empreendedores, competitivos (Bill Gates, Steve Jobs, e outros gurus da área de tecnologias não são recordes de vendas nas livrarias à toa)"; "no mundo dos negócios, no mercado, não há espaço para sentimentos", são veiculadas a todo o momento nos noticiários televisivos, nos livros de auto-ajuda, nas revistas e jornais (sobretudo empresariais) e em muitas escolas e universidades.

\section{A crítica do real a partir de Mafalda e sua turma e o imperioso "comprometimento" do professor}

A importância da crítica representa uma das preocupações mais importantes deste trabalho, que busca refletir sobre o ofício do professor de História e a possibilidade de se forjarem, coletivamente, na aula desta disciplina, sentidos contra-hegemônicos, ou seja, sentidos que vão de encontro ao projeto de classe burguês, à hegemonia desta classe. No entanto, é mister afirmar que ser crítico não significa necessariamente ser contra-hegemônico. Posições críticas a valores dominantes não necessariamente conformam uma contra-hegemonia. O Romantismo, por exemplo, movimento artístico, político e filosófico, surgido na Europa no fim do século XVIII, estabeleceu críticas importantes ao capitalismo, mas nem por isso foi contra-hegemônico, pois não propôs a superação do capital, não rompeu com o modelo burguês de sociedade, não forjou outra hegemonia. O mesmo se deu com o movimento da Contracultura na década de 1960, que 
criticou valores da cultura ocidental e construiu críticas às contradições e aos efeitos do capitalismo, sem no entanto, apontar para seu ocaso.

Conforme dito anteriormente, apesar de Quino não ser marxista ${ }^{14}$, de não defender o fim do capitalismo, o fim das classes, de crer que seus desenhos, seu trabalho, não sirvam de nada ${ }^{15}$, é possível que o professor de História (que também não precisa ser marxista para tal), a partir das críticas incisivas de Mafalda, suscite/construa, na interação com os alunos, sentidos contrahegemônicos, questionando, a partir da obra do artista argentino, os elementos característicos da sociedade burguesa analisados neste trabalho. Obviamente, para tal empreitada, é fundamental que o professor esteja comprometido com os interesses das classes dominadas (SILVA, 1996, p. 67), com a superação da dominação, sem os quais não é possível pensar em leituras contrahegemônicas da realidade. Estar comprometido com os "de baixo" significa também compreender a História como processo e não como o simples relato de algo que já passou, e refutar todo e qualquer refúgio na assepsia de uma História com pretensão à neutralidade (PINSKY, 2009, p. 9).

Como obra de arte, Mafalda explicita as contradições do momento histórico em que foi produzida, mesmo que seu autor não tenha tido esta intenção ao desenhá-la. Ciente disto, é possível se apropriar da obra de Quino em sala de aula, não apenas para conhecer/compreender melhor os anos 1960 e 1970 na América Latina, mas também a fim de provocar reflexões acerca das rupturas e sobretudo permanências oriundas deste período histórico, problematizando a sociedade de classes, o capital, o imperialismo, o modelo burguês de sociedade (expondo suas contradições), e costurando vieses contra-hegemônicos, ou seja, discutindo caminhos, possibilidades de construção de uma outra sociedade, de um outro mundo (perspectiva contrahegemônica).

A partir das reflexões de Barreto (1994, p. 65), defendemos a crítica como possibilidade de ruptura, a partir do questionamento, em sala de aula, dos elementos que sustentam, ideológica e materialmente, a hegemonia burguesa. Entendemos que a construção da polêmica na aula de História, pela via do lúdico, não é possível sem a crítica, entendida como o questionamento constante de diferentes idéias/sentidos, que não têm apenas um, mas muitos lugares (ORLANDI apud BARRETO, 1994, p. 66-67); como o deslocamento de pontos de vista, que faz com que os problemas assumam sempre novos aspectos, tornando incerto o já dito (ECO apud BARRETO, 1994, p. 67), e como desconstrução teórica, negando o pressuposto de um sentido único.

\footnotetext{
${ }^{14}$ Segundo Quino, em entrevista a Osvaldo Soriano (1972), “me sentiria muito feliz de poder crer em algo. Há pessoas que dizen que sou marxista, porém jamais li Marx; me da vergonha de dizê-lo, mas é assim. Não acredito em nada..." (SORIANO apud TRILLO; SACCOMANNO, 1980, p. 162).

${ }^{15}$ Dono de um pessimismo visceral, Quino, na mesma entrevista a Soriano (1972 apud TRILLO; SACCOMANNO, 1980, p. 162), afirma, após ser perguntado se seus trabalhos são essencialmente políticos, que sendo políticos ou não, seus trabalhos "não servem de nada", que o que faz "não muda nada". Para Quino, seu desenho tem caráter humanista e, se é político, é "antes de mais nada, uma política da condição humana".
} 
Com Orlandi (1988, p. 44), entendemos que o professor pode modificar as condições de produção da leitura do aluno e que existem, no espaço escolar, possibilidades de se criticar o que é apresentado como inexorável. É possível "apontar outras formas de ver, assumindo perspectivas diferentes, elas também produzidas na história da luta de classes, cravadas nos conflitos, mais ou menos evidentes, que marcam as relações sociais" (BARRETO, 1994, p. 167). Sob o conceito gramsciano de hegemonia, Barreto é incisiva quanto à imperiosa construção de outros sentidos na escola, de diferentes olhares e falas:

O que está pronto é o que já foi produzido e legitimado. Está posto e é dito de um lugar claramente demarcado. Interessa aos grupos hegemônicos, chocando-se com as grandes maiorias que não ocupam as mesmas posições de ver/falar. Na escola (grifo da autora), o pronto tem produzido sucessivos fracassos. Logo, é preciso encará-lo a partir de variadas perspectivas, no sentido de viabilizar produções com outros sentidos, no movimento do singular (autoritário, ideológico) para o plural (confronto de posições): a ser feito/produzido (BARRETO, 1994, p. 167).

Identificamo-nos com Barreto, em sua "proposta de ensino de leitura crítica" (BARRETO, 1994, p. 166), assumindo uma perspectiva de desafio, "talvez chocante" (BARRETO, 1994, p. 168), tendo em vista as atuais condições da escola no Brasil, sobretudo a pública: o quantitativismo dos índices em detrimento da qualidade do ensino; as péssimas condições de trabalho dos docentes, que vão desde a formação precária à remuneração quase que "simbólica"; a centralidade, ainda, do livro didático; o incômodo do aluno, que da escola o que mais abomina é a sala de aula; a distância professor-aluno, e a aparente resignação generalizada.

Nossa perspectiva é a de na sala de aula "se trabalhar em conjunto para construir em processo" (BARRETO, 1994, p. 170), solidariamente, onde professor e aluno aprendem ${ }^{16}$ um com o outro (não numa busca por respostas, mas, sobretudo, na elaboração de perguntas), e ambos ousam pensar/construir uma escola diferente - onde teoria e prática não são dicotômicas - para então, pensar/construir um mundo diferente. Entendemos a diferença de perspectiva, a contradição, inerente às relações de ensinar-aprender, um campo fecundo para se estimular a polêmica, imprescindível para se produzirem rupturas. Mais uma vez, é óbvio que o professor (em nosso caso, de História) deve estar comprometido com a mudança, com os interesses das classes dominadas, tendo clareza de que é um cidadão concreto numa sociedade também concreta, não sendo prudente, como afirma Barreto, dar as costas a ela. Com Barreto, perguntamos: "Nesta sociedade, embora não necessariamente lado a lado, vivem os alunos. De que lado fica o professor?" (BARRETO, 1994, p. 170).

\footnotetext{
16 "[...] o ensino se produz para que os alunos aprendam, com professores que sabem algumas coisas, que sempre sabem
} muito pouco, e que, portanto, têm muito a aprender com a produção do possível, a ser expandido" (BARRETO, 1994, p. 171). 
Gramsci dedicou bastante atenção, com frequência, à função do mestre. O filósofo sardo entendia que o mestre, imprescindível dentro da escola, correspondia a um professor "consciente de sua função", a um professor que assume seu papel dentro da escola. De acordo com Jesus (2005, p. 79), em Gramsci: "ser 'professor' implica uma função material de transmitir conhecimentos instruir - sem preocupação com a formação do homem - o educar". Nossa perspectiva no presente trabalho encontra eco nas palavras do intelectual gramsciano, que afirma que "estar consciente dos contrastes significa voltar-se para o ambiente que cerca a todos, com o objetivo de captar seu sentido e seus limites. Ao mestre compete criar os pressupostos para a superação da sociedade atual, apresentando valores que possibilitem esta superação".

Com as histórias em quadrinhos, defendemos um "outro" tipo de diálogo entre o professor de História e o aluno, um diálogo que do lúdico pode alcançar o polêmico (sobretudo as histórias em quadrinhos críticas, como Mafalda e sua turma); um diálogo que não refuta, mas ultrapassa os limites da linguagem escrita, de parâmetros mais "duros", abrangendo as demais linguagens que fazem parte do cotidiano das pessoas, e cuja articulação é essencial à produção dos sentidos (BARRETO, 1994, p. 171), sentidos que não se localizam apenas nos livros didáticos, na realidade concreta ou no imaginário/simbólico, mas nesta articulação.

A prática escolar, afirma Barreto, deve ser mais compromissada com o mundo exterior, menos fragmentada, mais aberta a novas formulações, e a escola, esta instituição na qual somos obrigados a ir desde pequenos, onde passamos grande parte do dia, onde somos avaliados, punidos disciplinarmente e onde reproduzimos rituais, deve "fazer mais sentido", para todos (BARRETO, 1994, p. 172). Obviamente, não estamos aqui desconsiderando os aspectos positivos do processo de escolarização, e com isso, talvez, municiando os que querem liquidá-la, desterritorializá-la. Trata-se de uma reflexão crítica acerca do caráter coercitivo da escola e do "pouco sentido" que tem no imaginário dos alunos, sobretudo.

Entendemos que os embates materiais e ideológicos pela construção de uma outra escola, democrática, plural, crítica, compromissada, desalienante, ocorrem tanto nas ruas, nas passeatas, assembléias, greves, quanto na sala de aula, privilegiado espaço de disputas, de construção coletiva do saber e por que não, numa perspectiva crítica e emancipadora, também de sentidos contra-hegemônicos.

A crítica de Quino, através de Mafalda e sua turma, possibilita inúmeros pontos de entrada para a análise crítica da sociedade burguesa, expondo suas contradições. Uma aula de História sintonizada com tal percepção pode construir, coletivamente, sentidos contra-hegemônicos em relação à hegemonia burguesa, questionando elementos característicos deste tipo de sociedade, como o individualismo, a competição, a "democracia", a "igualdade", o livre-comércio, dentre outros. O professor, sozinho, não é capaz de construir uma contra-hegemonia, processo histórico complexo, plural e dinâmico. A perspectiva, como dissemos, é sempre coletiva, compreendendo as histórias em quadrinhos como ponto de partida (e nunca de chegada) para uma análise crítica 
do real na aula de História e para atitudes críticas nas práticas sociais, em articulação com outras linguagens, outras formulações, outras abordagens da mesma forma críticas.

Temos a clareza de que as hq's não têm a capacidade de sozinhas, esgotarem as discussões e conteúdos da disciplina, ou ainda "transformarem" o aluno num indivíduo crítico como num passe de mágica. Como lembra Davies (1996), a escola, o professor, o aluno, fazem parte de uma sociedade de classes,

[...] cuja lógica maior é a constituição do indivíduo passivo, obediente, dócil, que encare a realidade atual como o "fim da História", um indivíduo que não se veja como sujeito do conhecimento e da história, que seja espectador da história, que não perceba a história em sua totalidade e temporalidades múltiplas.

Propomos "um" caminho, pensado a partir da prática em sala de aula, no sentido de tornar o ensino de História mais crítico, polêmico e, principalmente, mais sintonizado com o mundo "de fora" dos muros da escola, como ela heterogêneo, contraditório e caracterizado como um espaço de disputas, onde alternativas ao modelo burguês de sociedade podem - e devem - ser pensadas, debatidas, forjadas. Em nossa perspectiva, Mafalda e sua turma representam um poderoso canal de diálogo com este mundo, que não é exterior à escola, um mundo que dialeticamente está "fora" e "dentro" dela.

Nossas reflexões estão focadas na interação crítica professor-aluno, sob a perspectiva do professor, cuja atuação é chave para nossas pretensões. Na sociedade de classes em que vivemos, a História é feita não apenas pelas classes dominantes, mas pelo embate, material e ideológico, travado com as classes dominadas. Portanto, o ensino, o livro didático, não são "espelhos" dos interesses dominantes, tampouco o professor é um agente da ordem burguesa, podendo trabalhar em favor dos interesses populares em sala da aula (DAVIES, 1996). A perspectiva crítica do professor, sua formação teórica e política, assim como seu comprometimento com os grupos sociais subjugados, são fundamentais para que se construa um ensino de História crítico e emancipador. No entanto, obviamente as condições materiais do docente (remuneração, condições de trabalho, formação) influenciam no êxito ou no fracasso desta empreitada.

\section{Considerações Finais}

Após ser perguntado se é possível modificar algo através do humor, Quino afirmou certa vez: "Não. Acho que não. Mas ajuda. É aquele pequeno grão de areia com o qual contribuímos para que 
as coisas mudem". ${ }^{17}$ Apesar da resposta categórica, é fato que a obra de Quino contribuiu (e contribui) bastante para a crítica do senso comum, para a politização através da arte e, sobretudo, para uma leitura das décadas de 1960 e 1970 que, longe de ser neutra ou contemplativa, se posiciona e questiona a todo o momento os fatos, os costumes, a partir da visão que Quino tem do mundo, visão que, apesar de não romper com a sociedade de classes, tampouco defender a superação do capital, em muitas circunstâncias possibilita leituras contra-hegemônicas da realidade.

$\mathrm{Na}$ imperiosa tarefa de tornar os indivíduos efetivamente e conscientemente sujeitos da História, os educadores são agentes fundamentais, sobretudo aqueles que "enxergam" o mundo a partir de uma perspectiva contra-hegemônica, que estão comprometidos com as lutas dos dominados, que assumem um lugar na luta de classes em favor dos subjugados, que se indignam com uma educação que não problematiza a realidade e não oferece alternativas de mudança ao que já existe. Educadores que compreendem que reduzida à coerção, nenhuma classe consegue consolidar seu domínio, e que os grupos dominantes têm sobrevivido e obtido, historicamente, êxito na exploração e na opressão dos "de baixo", porque conseguem neutralizar áreas fundamentais do campo de batalha da cultura - como a escola - mantendo sua hegemonia.

Defender outra educação possível, outra escola, é defender outra sociedade, apontando para a superação da atual, burguesa e desigual, onde todos são iguais, mas alguns são mais iguais que os outros ${ }^{18}$. A crítica de Mafalda e sua turma aos elementos que caracterizam a sociedade burguesa - que também estão "dentro" da escola, como o individualismo, a desumanização, a competição - representa, como dissemos anteriormente, um pequeno "grão de areia" que encontramos para somar nas lutas contra-hegemônicas, na esperança de que outros grãos se juntem a nós.

\section{Referencias}

ACANDA, Jorge Luis. Sociedade civil e hegemonia. Rio de Janeiro: UFRJ, 2006.

ARAUJO, Tarso. Criador de Mafalda fala de pausa criativa e diz não ter pressa de voltar. Folha de São Paulo, São Paulo, maio 2010. Disponível em: <http://www1.folha.uol.com.br/ ilustrada/741360criador-de-mafalda-fala-de-pausa-criativa-e-diz-nao-ter-pressa-de-voltar.shtml $>$. Acesso em: jul. 2011.

BARRETO, Raquel G. Da leitura crítica do ensino para o ensino da leitura crítica. 1994. Tese (Doutorado em Educação) - Programa de Pós-Graduação em Educação, Faculdade de Educação da Universidade Federal do Rio de Janeiro, Rio de Janeiro.

${ }^{17}$ Em entrevista traduzida para o português no site Mafalda Online: http://www.mafalda.net/.

${ }^{18}$ Parafraseando George Orwell em $A$ revolução dos bichos. 
BOTTOMORE, Tom. Dicionário do pensamento marxista. Rio de Janeiro: Jorge Zahar, 2001.

CHAUÍ, Marilena. Conformismo e resistência: aspectos da cultura popular no Brasil. São Paulo: Brasiliense, 1986. . Simulacro e poder: uma análise da mídia. São Paulo: Fundação Perseu Abramo, 2006.

COUTINHO, Eduardo Granja. Processos contra-hegemônicos na imprensa carioca, 1889/1930. In: _. Comunicação e contra-hegemonia: processos culturais e comunicacionais de contestação, pressão e resistência. Rio de Janeiro: UFRJ, 2008. p. 65-89.

DAVIES, Nicholas. Livro didático: apoio ao professor ou vilão do ensino de História? Tecnologia Educacional, Rio de Janeiro, v. 24, n. 128, p. 10-12, jan./fev. 1996.

EAGLETON, Terry. Ideologia: uma introdução. São Paulo: Boitempo, 1997.

JESUS, Antonio Tavares. O Pensamento e a Pratica Escolar de Gramsci. 2. ed. Campinas: Autores e Associados, 2005.

KONDER, Leandro. A questão da ideologia. São Paulo: Cia das Letras, 2002.

LUYTEN, Sonia M. Bibe. Histórias em quadrinhos: leitura crítica. São Paulo: Paulinas, 1984.

MAFALDA online. Entrevista. Disponível em:<http://www.mafalda.net/>. Acesso em: abr. 2011.

MARX, Karl. Manuscritos econômico-filosóficos. São Paulo: Boitempo, 2008.

MARX, Karl; ENGELS, Friedrich. A ideologia alemã. São Paulo: Boitempo, 2009.

ORLANDI, Eni P. Discurso e leitura. São Paulo: Cortez, 1988.

ORWELL, George. A Revolução dos bichos. São Paulo: Círculo do Livro, 1974.

PINSKY, Jaime (Org.). O ensino de história e a criação do fato. São Paulo: Contexto, 2009.

QUINO. Toda Mafalda. Rio de Janeiro: Martins Fontes, 2002.

SILVA, Marcos A. da (Org.). Repensando a história. Rio de Janeiro: Marco Zero, 1996.

TRILLO, Carlos; SACCOMANNO, Guillermo. Historia de la historieta argentina. Buenos Aires: Record, 1980.

WILLIAMS, Raymond. Marxismo e literatura. Rio de Janeiro: Jorge Zahar, 1979.

\section{Recebido em 30/02/2012}

Aprovado em 30/05/2012 